\section{CLOSE RANGE}

\section{Some of China's many cities have} scientific expertise that complement each other, contributing to a rich and varied research environment.
BY PENG TIAN \& FLYNN MURPHY

$\mathrm{R}$ esearch papers that result from international collaborations have increased markedly since the Nature Index began tracking papers in 68 top journals in 2012, and Chinese research is no exception. But domestic partnerships remain a large part of the country's high-quality research output. In fact, partnerships between two Chinese institutions have significantly greater contributions to journals included in the index than partnerships between a Chinese and an international institution (see the tables, page S73).
The collaborations between institutions in mainland Chinese cities highlight the appeal of Beijing and Shanghai. Institutions in those cities formed the largest number of partnerships in 2016.

But beyond these metropolises, institutions in smaller cities have expertise that makes them strong collaborators in their own right. In the case of Kunming, the region's unique biodiversity is a boon for scientists interested in studying plants and ecology. Whereas Changchun in China's northeast has a long history specializing in chemistry research. 


\section{A CHEMISTRY HOTSPOT}

Changchun is sometimes called the Detroit of China. The capital of Jilin province in the northeast has for decades been the country's unofficial car manufacturing capital.

The city is also a hotspot of chemistry research. The Changchun Institute of Applied Chemistry (CIAC) has been a stronghold in this field since the 1970s. Last year more than $80 \%$ of the city's contribution to high-quality research in the Nature Index was in this field, led by Jilin University and CIAC, the city's top two institutions in the index in 2016.

\section{"COMMERCIALIZATION OF RESEARCH IS VERY RISKY."}

Changchun's partnerships with institutions in other Chinese cities increased from 100 in 2012 to 174 in 2016. In this context, a partnership occurs when researchers from organizations in Changchun co-author papers in index journals with scientists from institutions in other Chinese cities.

Changchun's strongest partnership last year was between the CIAC and the University of Chinese Academy of Sciences (UCAS) in Beijing, both part of the Chinese Academy of Sciences. All of CIAC's master's and PhD candidates are also students of UCAS.

Among CIAC's research divisions are several well-funded state key laboratories and CAS key laboratories. According to the institute's 2016 annual report, it received about 354 million RMB funding (US\$51 million) in 2015.

The CIAC-affiliated State Key Laboratory of Polymer Physics and Chemistry receives about a third of its funding from industry, says director Yang Xiaoniu. His lab, which works on polymer structure and properties, secures even more industry funding, between 50 and $70 \%$. In 2014 CIAC established a new company, Changchun A \& Z Science Co, to manufacture a new type of water lubricating bearing, based on Yang and his team's research.

Yang's research has had mixed success. His work on an efficient, cheap to manufacture variety of solar cells, known as donor-acceptor copolymer solar cells, has yet to achieve commercial reach, despite significant investments of time and money. "Commercialization of research is very risky," he says.

Finding local industry partners to translate research findings into products is an additional challenge for Changchun's research institutions. The region's business sector is dominated by largely inefficient state-owned businesses. Yang says opportunities for Changchun's institutions to cooperate with industry mostly come from businesses based in southern provinces that have become manufacturing hubs, such as Jiangsu and Zhejiang. His lab, for instance, mostly collaborates with businesses in southern provinces or overseas.

Changchun's academic-industry partnerships in the index between 2012 and 2016 reveal a similar trend. None of the 12 corporations with which the city's institutions

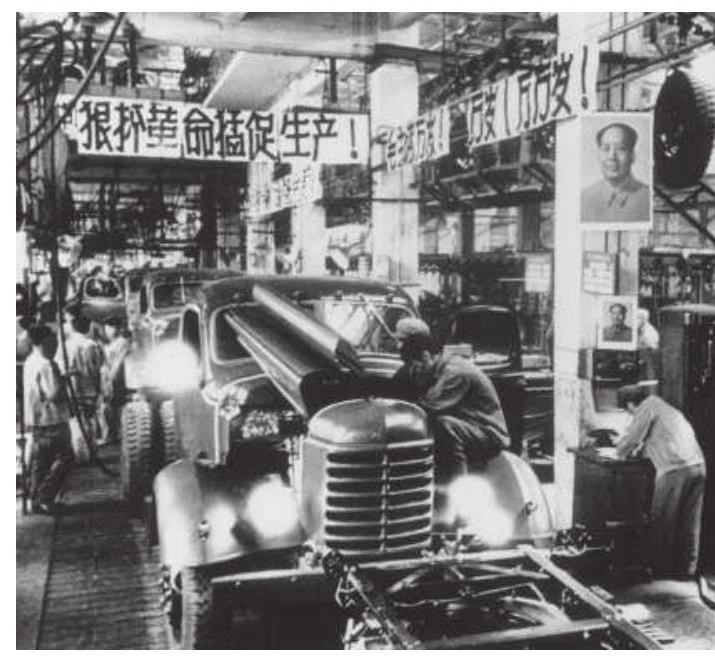

Changchun is the unofficial car manufacturing capital, sometimes called the Detroit of China.

coauthored papers were based in the city. The six Chinese corporate partners were based in either Beijing or Shanghai, or in cities in Zhejiang and Jiangsu provinces.

The more prosperous southern provinces are also drawing young educated people away from former industrial cities like Changchun. Several academics have told Nature Index that scientists are leaving Changchun's institutions such as CIAC for better career development and greater industry cooperation in southern cities. To stay competitive, CIAC has this year begun recruiting master's and $\mathrm{PhD}$ candidates from The University of Science and Technology of China in Hefei, a member of the C9 group of elite universities.

\section{CHANGCHUN'S CITY CONNECTIONS}

Institutions

in Changchun

collaborated with

190 institutions in

26 other cities in

mainland China in

2016. Connections are

ordered by number of

bilateral partnerships

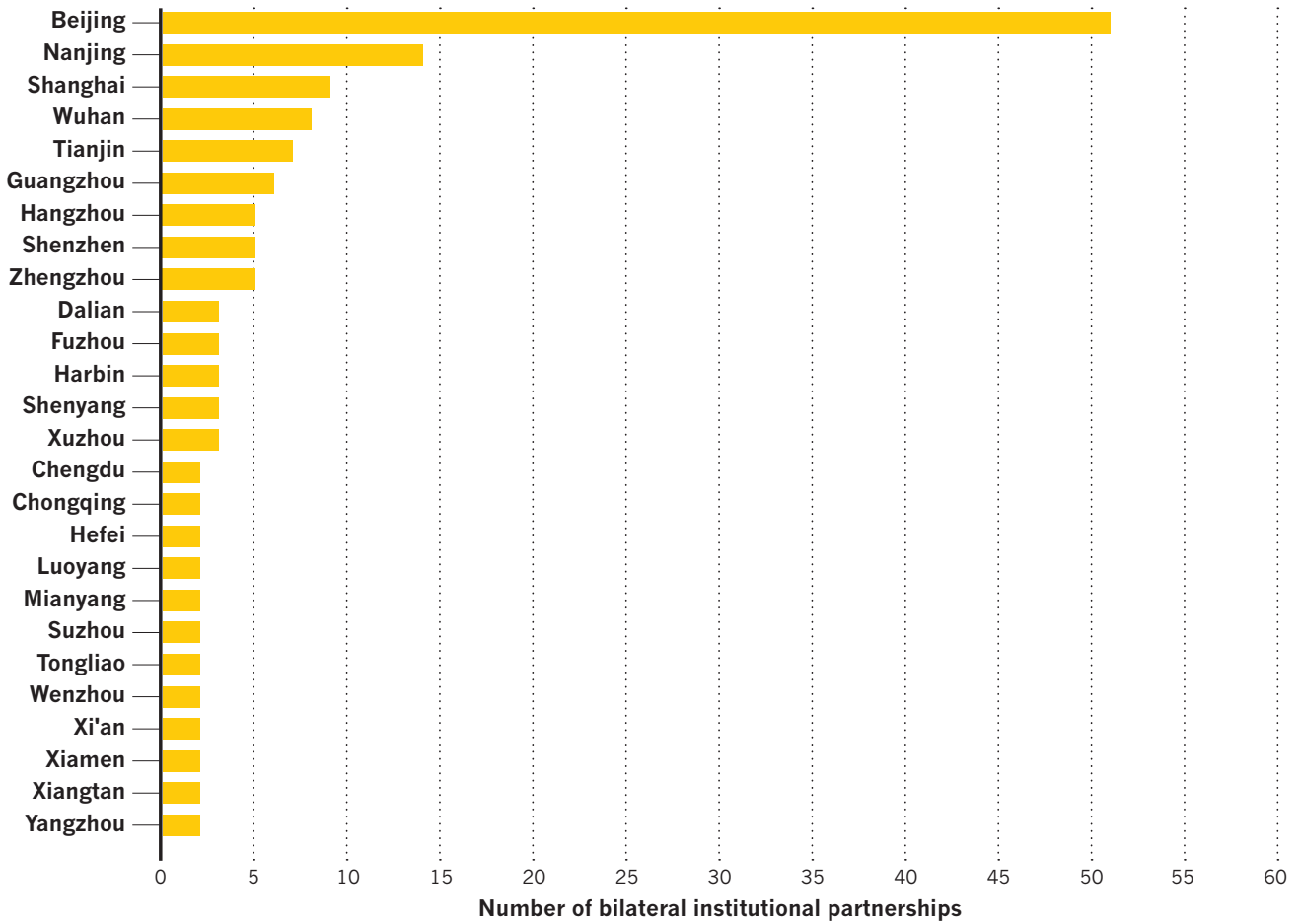



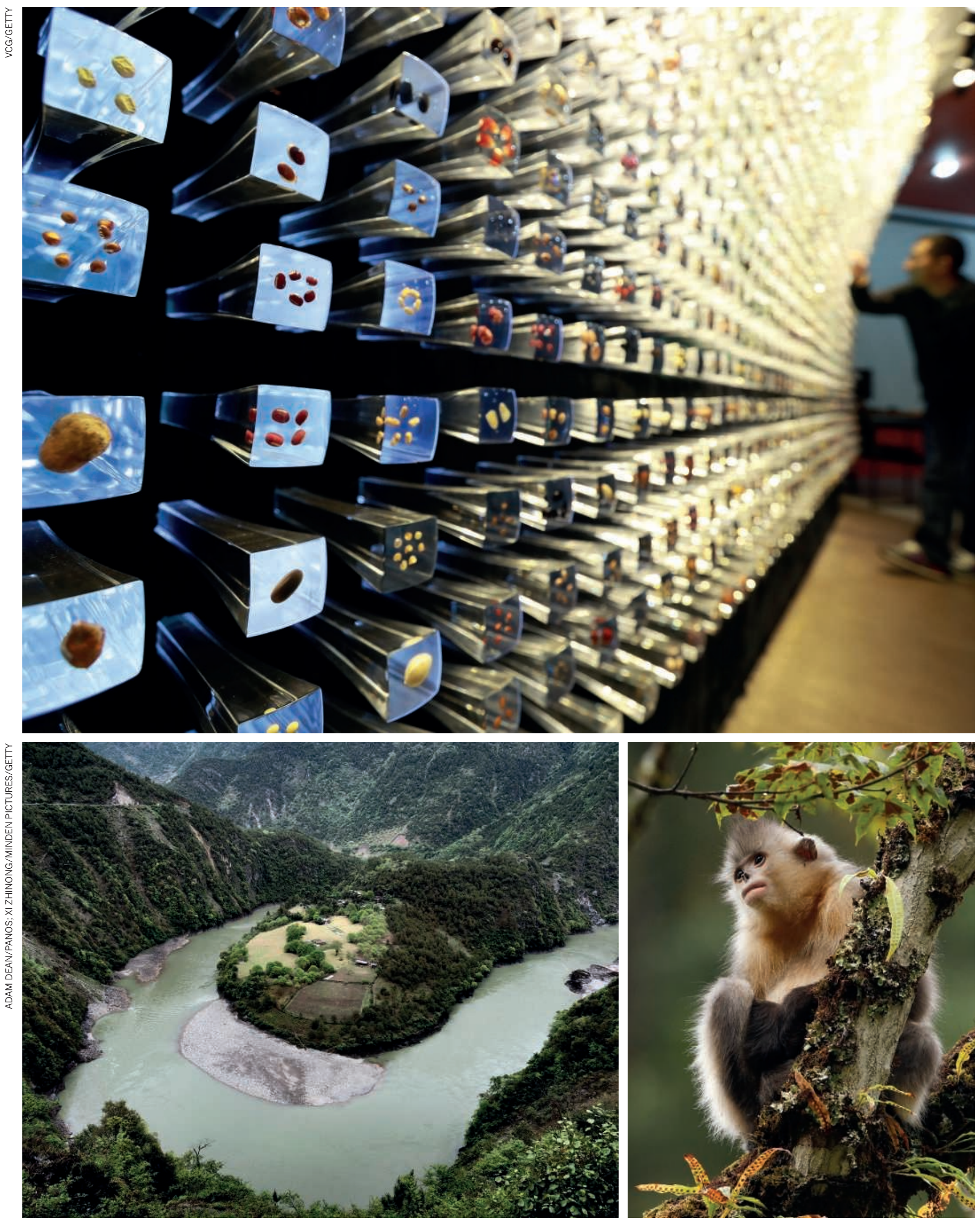

The Southwest China Germplasm Bank in Kunming was established by the Kunming Institute of Botany. The inland province of Yunnan is home to many rare plants, and the critically endangered Yunnan Snub-nosed monkey (bottom right). The Nujiang River (bottom left) snakes around a horseshoe bend in Bingzhongluo, Yunnan. The river originates in the Tibetan Plateau and travels through Myanmar, China and Thailand. 


\section{KUNMING'S NATURAL ADVANTAGE}

On paper, China's southwestern province of Yunnan is poor. It has one of the country's lowest GDPs per-capita. The region is also prone to devastating earthquakes.

Yet its capital Kunming belies its size when considering its value as a research hub. Last year scientists at the city's institutions formed 190 domestic research partnerships with other Chinese institutions to co-author papers included in the index. With a weighted fractional count (WFC) of 34.87, the research output of Kunming's institutions remains small compared to giants like Beijing (WFC 1,663.04) and Shanghai (WFC 734.03). But, it ranks 16 th of the 184 Chinese cities in the Nature Index for its number of domestic research partnerships.

$\mathrm{Xu}$ Jianchu, a pioneering Chinese ethno-ecologist, attributes this performance to scientists' fascination with Yunnan's cultural and biological diversity. The inland province contains more than half of China's plant and animal species. Although Yunnan spans just $4 \%$ of China's land mass, a comprehensive review published in Biodiversity \& Conservation in 2004 found it contained 1,836 vertebrate species, including the critically-endangered golden monkey, and around 18,000 higher plant species, including more than $40 \%$ of China's rare and endangered plants. $\mathrm{Xu}$, who is based at the Kunming Institute of Botany, said this diversity gave Kunmingbased scientists an advantage. "Any international and national partners who want to do research into plants, ecology, conservation - they need to collaborate with us," Xu said.

More than two thirds of Kunming's output on the Nature Index is the field of chemistry, with many articles investigating the chemical structures and processes of plants.

Xu said Yunnan sits at the nexus of three "biodiversity hotspots": the mountains of southwest China, the eastern Himalayas, and Indo-Burma in the south (it shares borders with Burma, Laos and Vietnam). It has 25 officially-recognized minority ethnic groups and dozens of languages.

$\mathrm{Xu}$ is collaborating with researchers from the Xinjiang Institute of Geography and Ecology, part of the Chinese Academy of Sciences, to develop an ecological calendar for the region

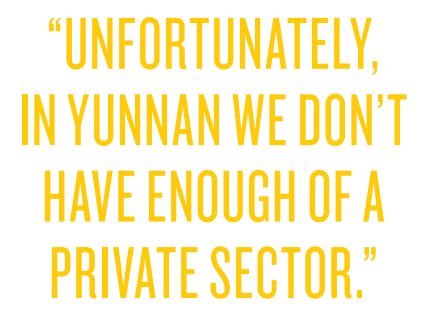

to monitor the impact of climate change on the mountain region using indicators from indigenous groups, as well as the group's own studies.

$\mathrm{He}$ is also working on a joint study of fungi with Guizhou University that includes researchers from Beijing. Yunnan's diverse fungi species are renowned across China where they are used in food and traditional Chinese medicine.

American social-ecological researcher R. Edward Grumbine first visited Yunnan in 2005 to understand the potential cultural and biodiversity impact of controversial efforts to dam the Nu river, which extends from the
Tibetan plateau to the Andaman Sea. Captivated by the region's diversity, Grumbine took on some small research projects while travelling between Yunnan and the US.

"Scholars who are interested in China, who do any kind of general homework at all, will come quickly to see the value of doing research in Yunnan," he told Nature Index from Arizona, where he now works for a non-profit organisation. One was early 20th-century Austrian-American explorer and botanist Joseph Rock, whose stonewalled former residence still sits outside the historical town of Lijiang, near where Grumbine conducted fieldwork.

From 2010 to 2014, he worked with Xu's team as a research fellow, part of a Chinese government effort to jump-start the publishing productivity of Chinese sciences in high-impact factor journals. About 150 international scholars were embedded in CAS research institutes across the country, he said. "Our job was to pursue whatever research we wanted and to publish in the most prestigious journals that we could manage, and then act as lightning rods, role models [for] teams full of Chinese researchers."

For Yunnan, efforts such as these are hampered by the brain drain that draws scientists to China's more developed coastal cities. "We've lost several groups of researchers in recent years. They went to Shenyang. They went to Shanghai."

$\mathrm{Xu}$ contrasted Kunming with the coastal boomtown of Shenzhen in China's southeast, where the private sector has attracted top talent. "Unfortunately, in Yunnan province we don't have enough of a private sector," he said. "We have government support, but compared to coastal areas the support is not so significant."

\section{KUNMING'S CITY} CONNECTIONS

Institutions in Kunming collaborated with 174 institutions in 28 other cities in mainland China in 2016. Connections are ordered by number of bilateral partnerships.

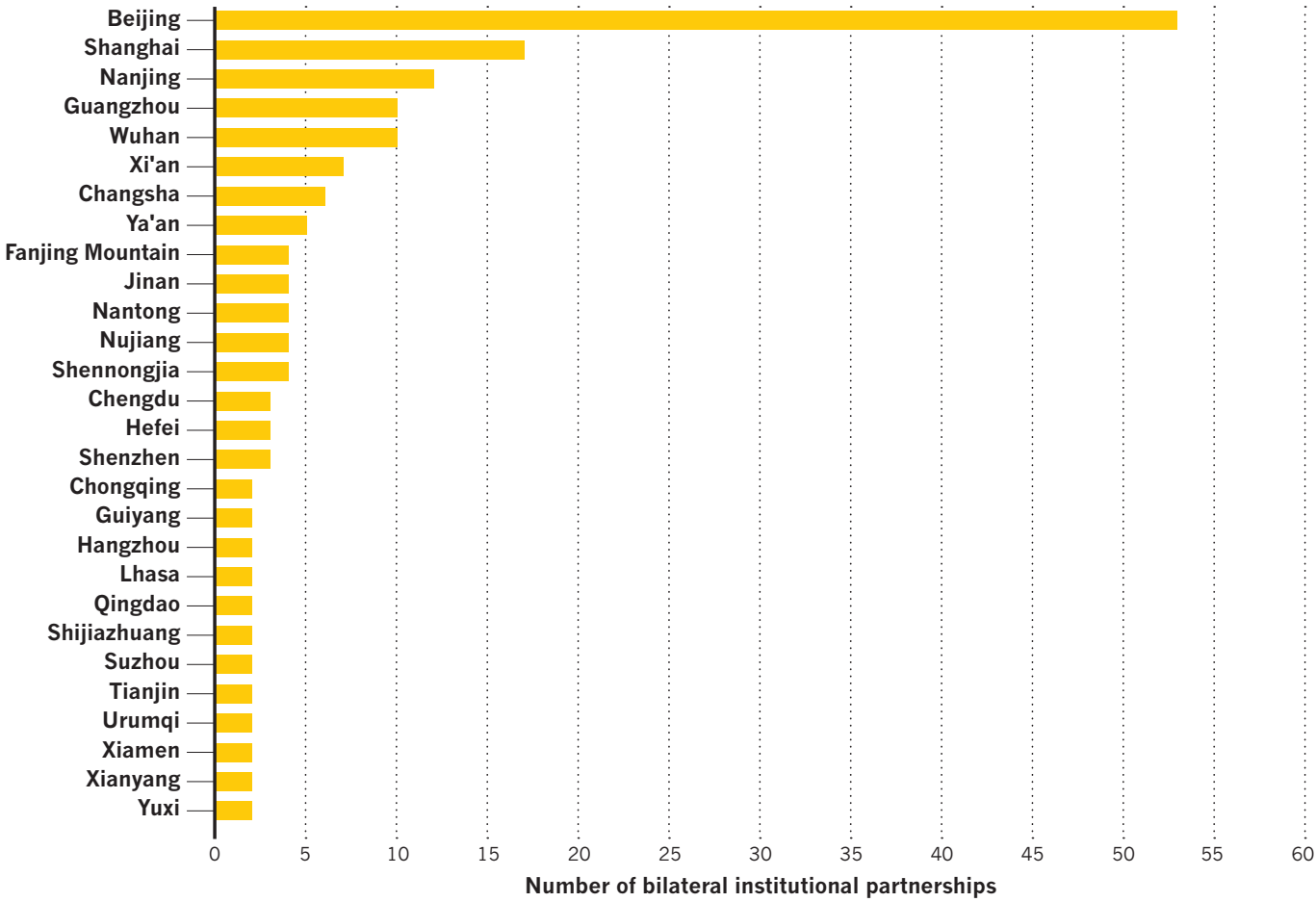

